\title{
PENGAMATAN PERUBAHAN LANJUT KEMATIAN DALAM MENGHINDARI MATI SURI
}

\author{
${ }^{1}$ Catherine Karundeng \\ James Siwu \\ ${ }^{2}$ Johannis Mallo
}

${ }^{1}$ Kandidat Skripsi Fakultas Kedokteran Universitas Sam Ratulangi Manado
${ }^{2}$ Bagian Ilmu Kedokteran Forensik Medikolegal Fakultas Kedokteran
Universitas Sam Ratulangi Manado
Email: catherinekarundeng09297@yahoo.com

\begin{abstract}
The purpose of this study to further assess changes in mortality in an effort to resolve and prevent cases of near death experience. The basis of the study of a science is Tanatology. Near death experience can occur due to the lack of a simple tool, but it can still be detected with sophisticated tools. For those with advanced medical equipment they can be proven that the three life support system is still functioning. This often leads to inner conflict. Nevertheless, physicians should be able to determine the best decision in order not to harm defining death and can help many people.
\end{abstract}

Keywords: death, tanatology, near death experience

\begin{abstract}
Abstrak: Penelitian ini bertujuan untuk mengetahui perubahan lanjut kematian dalam usaha untuk memecahkan serta menghindari kasus-kasus mati suri. Dasar dari ilmu yang mempelajari tentang kematian merupakan ilmu Tanatologi. Mati suri dapat terjadi karena kurangnya alat sederhana, namun masih dapat terdeteksi dengan alat canggih. Untuk itu dengan peralatan kedokteran canggih masih dapat dibuktikan bahwa ketiga sistem penunjang kehidupan masih berfungsi. Hal ini sering menimbulkan konflik batin. Walaupun demikian dokter harus dapat menentukan keputusan terbaik dalam mendefinisikan kematian agar tidak merugikan dan dapat membantu masyarakat banyak.
\end{abstract}

Kata kunci: kematian, tanatologi, mati suri 
Kematian seseorang pada saat sedang menjalani suatu tindakan medis seringkali menimbulkan keragu-raguan bagi para dokter yang merawat maupun pada keluarga pasien, tentang mekanisme ataupun sebab kematian yang sebenarnya. Apabila para dokter menganggap bahwa sebab kematian pasien yang dirawatnya menimbulkan keragu-raguan, maka mereka akan meminta persetujuan keluarga pasien untuk melakukan pemeriksaan lanjutan, mulai berupa tindakan autopsi klinis. Kecurigaan adanya tindakan mal praktek juga kadangkala muncul di pihak keluarga pasien., ${ }^{1,9}$

Beberapa kasus kematian di Indonesia kebanyakan dikarenakan persediaan peralatan kedokteran yang kurang canggih. Peralatan tersebut tidak terdapat di daerah-daerah terpencil. Banyak pedalaman yang masih membutuhkan pelayanan dan persedian peralatan kedokteran yang modern. Oleh karena itu banyak dokter melakukan tindakan medis, kemudian pasien/korban tidak tertolong dan dokter langsung mendefinisikan kematian yang terlalu terburu-buru tanpa ada standar prosedur dan standar profesi. ${ }^{1}$

Pada dasarnya, kematian pada saatnya dilakukan tindakan medis dapat terjadi sebagai akibat dari:

1. Sebagai akhir dari perjalanan penyakitnya (alamiah).

2. Sebagai manifestasi dari salah satu risiko atau komplikasi dari tindakan medis tersebut. Risiko adalah suatu kemungkinan yang telah dapat diperkirakan sebelumnya (foreseeable) atau dapat pula tidak dapat diperkirakan sebelumnya (unforeseeable). Sebagian dari risiko biasanya dapat dihindari (avoidable) dan sebagian lagi tidak dapat dihindarkan (unavoidable). Risiko dapat merupakan akibat dari tindakan, akibat dari obat-obatan yang digunakan (misalnya pada anastesi), akibat dari situasi dan kondisi tertentu dari pasien sendiri, dan sebagai akibat dari reaksi alergi. Tim medis bertanggung jawab atas kematian tersebut apabila mereka tidak melakukan tindakan sesuai dengan standar prosedur dan standar profesi.
3. Sebagai hasil dari kecelakaan medik (medical mishap). Peristiwa ini sama sekali tidak dapat diperkirakan sebelumnya (unforseeable) sehingga tentu saja bersifat tidak dapat dihindari (unavoidable). WMA menyebutnya sebagai untoward results. Tim medis umumnya tidak dapat dipertanggungjawabkan pada peristiwa ini.

4. Sebagai hasil dari kelalaian medik. Lalai memiliki arti bahwa seseorang melakukan tindakan tertentu padahal orang lain yang berkualifikasi sama tidak akan melakukannya bila menghadapi situasi-kondisi yang sama, atau seseorang tidak melakukan tindakan tertentu padahal orang lain yang berkualifikasi sama akan melakukannya. Suatu peristiwa dianggap suatu kelalaian apabila memenuhi 4 syarat, yaitu: 1) adanya kewajiban untuk melakukan atau untuk tidak melakukan sesuatu (duty), 2) adanya pelanggaran atas kewajiban tersebut (derelection of that duty), 3) terjadinya cedera atau kerugian (damage), 4) yang memiliki hubungan sebab akibat dengan pelanggaran kewajiban diatas (direct causalship).

5. Sebagai hasil dari kesengajaan. Dalam upaya membuktikan peristiwa apa yang sebenarnya terjadi maka diperlukan pemeriksaan pasien/korban dengan seksama, termasuk dilakukannya autopsi apabila diperlukan. Selain itu, rekam medis pasien perlu dianalisis dan dicari asosiasinya dengan temuan autopsi. Penilaian tesebut sebaiknya melibatkan peer group sebagai saksi ahli guna memberikan pandangannya tentang peristiwa apa yang sebenarnya terjadi, apakah peristiwa tersebut suatu untoward result ataukah suatu resiko yang tidak dapat diprediksi sebelumnya, bagaimana standar prosedur yang berlaku, apakah peristiwa sesuai dengan standar prosedur yang berlaku, serta apakah telah terjadi pelanggaran atas standar. ${ }^{1}$

Dengan perkembangan kemajuan teknologi, di samping dapat membawa 
dampak positif dapat juga membawa dampak negatif. Dampak positif seperti semakin canggih pemeriksaan medik yang dilakukan serta peralatan kedokteran yang digunakan, semakin baik untuk membantu standar prosedur dan profesi yang berlaku. Tetapi di satu sisi berdampak negatif bagi sekelompok pelayanan masyarakat yang kurang pengadaan peralatan canggih, sehingga banyak dokter mendefinisikan kematian hanya berdasarkan peralatan sederhana yang ada melainkan secara terburu-buru. Situasi ini banyak menyebabkan keraguan bagi para dokter dan ternyata setelah dilakukan pemeriksaan lebih lanjut tidak ditemukan tanda-tanda kematian yang pasti dan perubahan-perubahan lanjut setelah kematian. ${ }^{1}$

Oleh karena itu ada beberapa kasus pasien yang dinyatakan telah mati secara klinis yaitu terhentinya fungsi sistem penunjang kehidupan, yang terdiri dari susunan saraf pusat, sistem kardiovaskular, dan sistem pernapasan. Ketiga sistem ini tidak terdeteksi aktifitasnya hanya dengan alat sederhana, namun masih dapat terdeteksi dengan alat canggih. Untuk itu baik untuk para dokter dengan peralatan kedokteran canggih masih dapat dibuktikan bahwa ketiga sistem penunjang kehidupan tersebut masih berfungsi atau bersifat sementara yang biasanya disebut dengan mati suri. Mati suri sering ditemukan pada kasus keracunan obat tidur, tersengat aliran listrik, kedinginan, mengalami cardiac arrest, dan tenggelam. ${ }^{1,2,4,5}$

Dasar dari kejadian ini adalah tentang ilmu Tanatologi. Banyak dokter belum terlalu mengerti dan paham tentang ilmu tanatologi. Ilmu tanatologi yang dimaksudkan adalah ilmu yang mempelajari tentang kematian dan proses tahapan lanjut setalah kematian serta faktor yang mempengaruhinya. Dalam ilmu tanatogi ini kita dapat mengetahui tanda-tanda pasti kematian, perubahanperubahan fisiologis saat kematian dan setelah kematian. Ilmu ini juga merupakan tujuan akhir untuk memperkirakan saat kematian atau lamanya mati seorang mayat. ${ }^{1,2,4}$
Berdasarkan pada hal diatas, maka dapat dirumuskan beberapa permasalahan sebagai berikut:

1. Bagaimanakah perubahan-perubahan lanjut setelah kematian?

2. Bagaimanakah peranan ilmu Tanatologi dalam usaha untuk memecahkan kasus-kasus mati suri?

\section{METODE PENELITIAN}

Penelitian dari judul ini merupakan jenis penelitian deskriptif dan merupakan suatu tinjauan pustaka (literatur review). Penelitian ini merupakan kesimpulan dari beberapa jurnal yang bersifat deduktif dan induktif.

\section{HASIL PENELITIAN DAN BAHASAN}

\section{KEMATIAN DAN MATI SURI}

Kematian menurut ilmu Kedokteran dikenal dengan ilmu Tanatologi. Ilmu yang berasal dari kata thanatos (yang berhubungan dengan kematian) dan logos (ilmu). Jadi, Tanatologi adalah bagian dari Ilmu Kedokteran Forensik yang mempelajari kematian dan perubahan yang terjadi setelah kematian serta faktor yang mempengaruhi perubahan tersebut. Dalam Tanatologi dikenal beberapa istilah kedokteran tentang mati, yaitu mati somatis (mati klinis), mati suri, mati seluler, mati serebral dan mati otak (mati batang otak). ${ }^{2,9}$

Mati Suri (suspended animation, apparent death) adalah terhentinya ketiga sistem kehidupan penunjang kehidupan,yang terdiri dari susunan saraf pusat, sistem kardiovaskular, dan sistem pernapasan yang ditentukan dengan alat kedokteran sederhana seperti memeriksa denyut jantung dengan stetoskop. Dengan peralatan kedokteran canggih masih dapat dibuktikan bahwa ketiga sistem tersebut masih berfungsi atau bersifat sementara seperti memeriksa denyut nadi karotis. Mati suri sering ditemukan pada kasus keracunan obat tidur, tersengat aliran listrik, kedinginan, mengalami cardiac arrest, dan tenggelam. ${ }^{2,45}$

\section{A. Bioetika}

Sepanjang perjalanan sejarah dunia Kedokteran, banyak definisi dan paham mengenai bioetika yang dilontarkan oleh para 
ahli etika dari berbagai belahan dunia Pendapat-pendapat ini dibuat untuk merumuskan suatu pemahaman bersama tentang apa itu bioetika. ${ }^{7}$

Bioetika berasal dari kata bios yang berati kehidupan dan ethos yang berarti norma-norma atau nilai-nilai moral. Bioetika merupakan studi interdisipliner tentang masalah yang ditimbulkan oleh perkembangan di bidang biologi dan ilmu kedokteran baik skala mikro maupun makro, masa kini dan masa mendatang. Bioetika mencakup isu-isu sosial, agama, ekonomi, dan hukum bahkan politik. Bioetika selain membicarakan bidang medis, seperti abortus, euthanasia, transplantasi organ, teknologi reproduksi butan, dan rekayasa genetik, membahas pula masalah kesehatan, faktor budaya yang berperan dalam lingkup kesehatan masyarakat, hak pasien, moralitas penyembuhan tradisional, lingkungan kerja, demografi, dan sebagainya. Bioetika memberi perhatian yang besar pula terhadap penelitian kesehatan pada manusia dan hewan percobaan. $^{7}$

Menurut F. Abel, Bioetika adalah studi interdisipliner tentang masalah-masalah yang ditimbulkan oleh perkembangan biologi dan kedokteran, tidak hanya memperhatikan masalah-masalah yang terjadi pada masa sekarang, tetapi juga memperhitungkan timbulnya masalah pada masa yang akan datang. $^{3}$

\section{B. Kaidah dasar moral}

Kaidah-kaidah bioetik merupakah sebuah hukum mutlak bagi seorang dokter. Seorang dokter wajib mengamalkan prinsip yang ada dalam kaedah tersebut, tetapi pada beberapa kasus, karena berbeda-beda kondisi, satu prinsip menjadi lebih penting dan sah untuk digunakan dengan mengorbankan prinsip yang lain. Kondisi seperti ini disebut Prima Facie. Konsil Kedokteran Indonesia, dengan mengadopsi prinsip etika kedokteran barat, menetapkan bahwa praktik kedokteran Indonesia mengacu kepada 4 kaidah dasar moral yang sering juga disebut kaidah dasar etika kedokteran atau bioetika, yaitu:

\section{Beneficence}

Berbuat baik (beneficence). Selain menghormati martabat manusia, dokter juga harus mengusahakan agar pasien yang dirawatnya terjaga keadaan kesehatannya (patient welfare). Pengertian "berbuat baik" diartikan bersikap ramah atau menolong, lebih dari sekedar memenuhi kewajiban. Tindakan berbuat baik (beneficence), yaitu:

\section{General beneficence :}

1) Melindungi \& mempertahankan hak yang lain

2) Mencegah terjadi kerugian pada yang lain

3) Menghilangkan kondisi penyebab kerugian pada yang lain

\section{Specific beneficence :}

1) Menolong orang cacat

2) Menyelamatkan orang dari bahaya

3) Mengutamakan kepentingan pasien

4) Memandang pasien/keluarga/sesuatu tak hanya sejauh menguntungkan dokter/rumah sakit/pihak lain

5) Maksimalisasi akibat baik (termasuk jumlahnya lebih besar dari akibat-akibat buruk yang dapat terjadi)

6) Menjamin nilai-nilai pokok kemanusiaan seperti apa saja yang ada, pantas (elok) kita bersikap baik terhadapnya.

2. Non-Maleficence

Tidak berbuat yang merugikan (nonmaleficence). Praktik Kedokteran haruslah memilih pengobatan yang paling kecil risikonya dan paling besar manfaatnya. Pernyataan kuno: first, do no harm, tetap berlaku dan harus diikuti. Sisi komplementer beneficence dari sudut pandang pasien, seperti :

a. Tidak boleh berbuat jahat (evil) atau membuat derita (harm) pasien

b. Minimalisasi akibat buruk 
Kewajiban dokter untuk menganut ini berdasarkan hal-hal :

a. Pasien dalam keadaan amat berbahaya atau berisiko hilangnya sesuatu yang penting

b. Dokter sanggup mencegah bahaya atau kehilangan tersebut

c. Tindakan kedokteran tadi terbukti efektif

d. Manfaat bagi pasien lebih besar daripada kerugian dokter (hanya mengalami risiko minimal).

\section{Justice (keadilan)}

Perbedaan kedudukan sosial, tingkat ekonomi, pandangan politik, agama dan faham kepercayaan, kebangsaan dan kewarganegaraan, status perkawinan, serta perbedaan jender tidak boleh dan tidak dapat mengubah sikap dokter terhadap pasiennya. Tidak ada pertimbangan lain selain kesehatan pasien yang menjadi perhatian utama dokter, seperti:

a. Treat similar cases in a similar way $=$ justice within morality.

b. Memberi perlakuan sama untuk setiap orang (keadilan sebagai fairness) yakni :

1) Memberi sumbangan relatif sama terhadap kebahagiaan diukur dari kebutuhan mereka (kesamaan sumbangan sesuai kebutuhan pasien yang memerlukan/membahagiakann ya)

2) Menuntut pengorbanan relatif sama, diukur dengan kemampuan mereka (kesamaan beban sesuai dengan kemampuan pasien).

c. Tujuan kaedah dasar ini menjamin nilai tak berhingga setiap pasien sebagai mahluk berakal budi atau bermartabat, khususnya yang berhak dan yang baik.
1) Jenis keadilan : Komparatif (perbandingan antar kebutuhan penerima)

2) Distributif (membagi sumber) adalah kebajikan membagikan sumber-sumber kenikmatan dan beban bersama, dengan cara merata, sesuai keselarasan sifat dan tingkat perbedaan jasmani-rohani dan juga secara material kepada :

a) Setiap orang andil yang sama

b) Setiap orang sesuai dengan kebutuhannya

c) Setiap orang sesuai upayanya.

d) Setiap orang sesuai kontribusinya

e) Setiap orang sesuai jasanya

f) Setiap orang sesuai bursa pasar bebas

d. Sosial adalah kebajikan melaksanakan dan memberikan kemakmuran dan kesejahteraan bersama, yakni:

1) Utilitarian yaitu memaksimalkan kemanfaatan publik dengan strategi menekankan efisiensi social dan memaksimalkan nikmat dan keuntungan bagi pasien.

2) Libertarian yaitu menekankan hak kemerdekaan social ekonomi (mementingkan prosedur adil > hasil substantif/materiil).

3) Komunitarian yaitu mementingkan tradisi komunitas tertentu

4) Egalitarian adalah kesamaan akses terhadap nikmat dalam hidup yang dianggap bernilai oleh setiap individu rasional (sering menerapkan kriteria material kebutuhan dan kesamaan).

e. Hukum (umum) :

1) Tukar menukar menjadi suatu kebajikan memberikan / mengembalikan hak-hak kepada yang berhak. 
2) Pembagian sesuai dengan hukum (pengaturan untuk kedamaian hidup bersama) mencapai kesejahteraan umum.

4. Autonomi

Menghormati martabat manusia (respect for person/autonomy). Menghormati martabat manusia. Pertama, setiap individu (pasien) harus diperlakukan sebagai manusia yang memiliki otonomi (hak untuk menentukan nasib diri sendiri), dan yang kedua, setiap manusia yang otonominya berkurang atau hilang perlu mendapatkan perlindungan. ${ }^{3}$

Menurut pandangan Kant ${ }^{3}$, yaitu otonomi kehendak (otonomi moral) adalah kebebasan bertindak, memutuskan (memilih) dan menentukan diri sendiri sesuai dengan kesadaran terbaik bagi dirinya yang ditentukan sendiri tanpa hambatan, paksaan atau campur-tangan pihak luar (heteronomi), suatu motivasi dari dalam berdasar prinsip rasional atau self-legislation dari manusia.

Menurut pandangan J. Stuart Mill ${ }^{3}$, yaitu otonomi tindakan/pemikiran (otonomi individu) adalah kemampuan melakukan pemikiran dan tindakan (merealisasikan keputusan dan kemampuan melaksanakannya), hak penentuan diri dari sisi pandang pribadi. ${ }^{3,7}$

\section{Prima Facie}

Dalam kondisi atau konteks tertentu, seorang dokter harus melakukan pemilihan 1 kaidah dasar etik terabsah sesuai konteksnya berdasarkan data atau situasi konkrit terabsah. Dalam penanganan pasien di klinik, sesuai indikasi medik, pengelolaan juga ditentukan oleh seni berbasis KDB (kaedah dasar moral). Asas prima facie mengisyaratkan KDB yang lama akan ditinggalkan diganti dengan KDB baru yang lebih absah. Inilah yang disebut pemilihan berdasarkan asas prima facie. ${ }^{8}$

\section{Pembenaran bioetika}

Pembenaran bioetika dapat terjadi dilema etik dikarenakan alat kedokteran yang sederhana dan kurang pengadaan alat kedokteran canggih, bertindak dengan bijaksana berdasarkan norma moral yang hierarkinya lebih tinggi dari norma hukum dan norma sopan santun serta berhati-hati dalam mendefinisikan kematian dan harus berpedoman pada Kode Etik Kedokteran (KODEKI). ${ }^{1}$

Norma dalam etika kedokteran (EK) :

1. Merupakan norma moral yang hierarkinya lebih tinggi dari norma hukum dan norma sopan santun (pergaulan)

2. Fakta fundamental hidup bersusila yaitu etika mewajibkan dokter secara mutlak, namun sekaligus tidak memaksa. Jadi dokter tetap bebas bisa menaati atau masa bodoh. Bila melanggar insan kamil (kesadaran moral = suara hati) akan menegur sehingga timbul rasa bersalah, menyesal, serta tidak tenang. ${ }^{3,8}$

\section{Sifat Etika Kedokteran :}

1. Etika khusus (tidak sepenuhnya sama dengan etika umum)

2. Etika sosial (kewajiban terhadap manusia lain / pasien).

3. Etika individual (kewajiban terhadap diri sendiri/selfimposed zelfoplegging)

4. Etika normatif (mengacu ke deontologis, kewajiban ke arah normanorma yang seringkali mendasar dan mengandung 4 sisi kewajiban (gesinnung) yakni diri sendiri, umum, teman sejawat dan pasien/klien \& masyarakat khusus lainnya)

5. Etika profesi (biasa):

a. bagian etika sosial tentang kewajiban \& tanggungjawab profesi

b. bagian etika khusus yang mempertanyakan nilai-nilai, norma-norma/ kewajibankewajiban dan keutamaankeutamaan moral

c. Sebagian isinya dilindungi hukum, misal hak kebebasan untuk menyimpan rahasia pasien/rahasia jabatan (verschoningsrecht) 
d. Hanya bisa dirumuskan berdasarkan pengetahuan \& pengalaman profesi kedokteran.

e. Untuk menjawab masalah yang dihadapi (bukan etika apriori); karena telah berabad-abad, yangbaik \& yang-buruk tadi dituangkan dalam kode etik (sebagai kumpulan norma atau moralitas profesi)

f. Isi dari 2 norma pokok :

1) sikap bertanggungjawab atas hasil pekerjaan dan dampak praktek profesi bagi orang lain

2) bersikap adil dan menghormati Hak Asasi Manusia (HAM).

6. Etika profesi luhur/mulia :

Isi dari 2 norma etika profesi biasa ditambah dengan :

a. Bebas pamrih (kepentingan pribadi dokter)

b. Ada idealisme merupakan tekad untuk mempertahankan cita-cita luhur/etos profesi sama dengan l'esprit de corpse pour officium nobile

7. Ruang lingkup kesadaran etis yakni keprihatinan terhadap krisis moral akibat pengaruh teknologisasi dan komersialisasi dunia kedokteran., ${ }^{3,8}$

\section{SIMPULAN}

Mati suri (apparent death, suspended death, near death experiences) merupakan proses vital dalam tubuh menurun sampai taraf minimum untuk kehidupan, sehingga secara klinis sama dengan orang mati dimana dengan peralatan kedokteran canggih masih dapat dibuktikan bahwa ketiga sistem penunjang kehidupan yaitu pernapasan, kardiovaskuler, serta otak masih berfungsi.

Telah dikenal beberapa teori mengenai mati suri ini, yaitu teori lobus temporal, teori kekurangan oksigen atau kelebihan karbon dioksida, serta teori halusinasi. Untuk menentukan mati suri (near death experiences) dapat dilakukan dengan skala NDE Greyson, menggunakan kuesioner yang terdiri dari enam belas pertanyaan, kuesioner ini telah divalidasi dan sesuai dengan standar. Seseorang yang pernah mengalami mati suri mengalami beberapa perubahan. Perubahan-perubahan yang terjadi setelah mengalami mati suri terdiri dari perubahan psikologis, perubahan fisiologis, perubahan spiritual. $^{8}$

Asas primafacie menjadi dasar pembenaran bioetika. Para tim medis berhatihati agar tidak terjadi dilema etik dalam mendefinisikan kematian sehingga tidak menyebabkan mati suri. Pembenaran bioetika terjadi berdasarkan norma kedokteran seperti norma moral yang hierarkinya lebih tinggi dari norma hukum dan norma sopan santun juga harus berpedoman pada Sifat Etika kedokteran dan Kode Etik Kedokteran (KODEKI). ${ }^{8}$

\section{DAFTAR PUSTAKA}

1. Budiyanto Arif, Widiatmaka W, Sudiono S, Mun'im W.A.T, Sidhi, Hertian S, dkk. 1997. Ilmu Kedokteran Forensik. Bagian Kedokteran Forensik Fakultas Kedokteran Universitas Indonesia. Jakarta.h. 25-36.

2. Wahyuni Ririn.2011 (http://www.scribd.com/doc/7851202 4/TANATOLOGI)

3. Jumat 9/11/2007

(http://yusufalamromadhon.blo gspot.com/2007/11/kaidahdasar-etikabioetikakedokteran.html)

4. Sampurna B, Samsu Z, Siswaja T. D. Peranan Ilmu Forensik Dalam Penegakan Hukum. Cetakan Pertama. Februari 2008.

5. Knight Bernard. Simpson's Forensic Medicine. Elevent Edition. 1997.

6. Idries Abdul M. 2008.

Penerapan Ilmu Kedokteran

Forensik dalam proses penyidikan. CV Sagung Seto. Jakarta.

7. Putra,E. Primus. 21 October 2011

(http://etgalputra.blogspot.com/2011/10/m akalah-bioetika-pembahasankasus.html) 
8. Humaryanto.2011

(https://docs.google.com/viewe $\mathrm{r} ? \mathrm{a}=\mathrm{v} \& \mathrm{q}=$ =cache:Bf9bawlanjAJ :fkunja2010.files.wordpress.co m/2011/02/kaidah-dasarbioetika.ppt+bioetika+kedokter an+adalah\&hl=id\&gl=id\&pid= bl\&srcid=ADGEESiJLcb5IheF FnszYAC- m57sH-

aYyaycNC7oWV03PHsFHOX
JzWCJajNLAoLwAJzkkWKG IDNiVtQPVLTbX7GuYnNqgd tQxUK190Ap1oMjzXWKKN UO31jFKKNTjuixaKgYXmlE io\&sig=AHIEtbQcaZQ96dgR RzyExKTc-p08Wn0FFA)

9. Fitricia R.2011

(http://repository.usu.ac.id/bitst ream/123456789/21606/4/Cha pter\%20II.pdf) 